\title{
MODERASI ISLAM (WASATHIYYAH) DI TENGAH PLURALISME AGAMA INDONESIA
}

\author{
Busyro \\ IAIN Bukittinggi, busyro.pro18@gmail.com \\ Aditiya Hari Ananda \\ IAIN Bukittinggi, aditiyahariananda@gmail.com \\ Adlan Sanur Tarihoran \\ IAIN Bukittinggi, adlansanun@gmail.com
}

\begin{abstract}
The State of Indonesia is a country that is plural in terms of religion, culture and ethnicity. This can be a potential progress of the nation and vice versa can also threaten the existence of the State. The problem that is often highlighted is religious pluralism, because religion is something that is more sensitive than other differences. Islam in Indonesia is the majority religion which must take a role in stabilizing the life of the state. A moderate view of religious diversity in Indonesia must always be fostered to make Indonesia a peaceful country in diversity. Therefore, efforts are needed on how to make Islamic moderation as a way to accommodate religious pluralism in Indonesia. From the discussion it can be concluded that Islam does not consider all religions to be the same but treats all religions the same as promoting tasamub (tolerance), then shura (deliberation) between religions, and has a musawah attitude (non-discriminatory).
\end{abstract}

Keywords: Islamic Moderation, Religious Pluralism, Plurality.

\begin{abstract}
Abstrak
Negara Indonesia merupakan Negara yang majemuk dari sisi agama, budaya, dan suku. Hal ini dapat menjadi potensi kemajuan bangsa dan sebaliknya juga dapat mengancam eksistensi Negara. Persoalan yang sering menjadi sorotan adalah pluralisme agama, karena agama merupakan sesuatu yang lebih sensitive dibandingkan dengan perbedaan lainnya. Islam di Indonesia merupakan agama mayoritas yang harus mengambil peran dalam menstabilkan kehidupan bernegara. Pandangan yang moderat tentang keragaman agama di Indonesia barus selalu dipupuk untuk menjadikan Indonesia menjadi Negara yang damai dalam kemajemukan. Oleh karena itu diperlukan upaya bagaimana menjadikan moderasi Islam sebagai cara untuk mengakomodir pluralisme agama di Indonesia. Dari pembahasan dapat disimpulkan bahwa Islam tidak menganggap semua agama itu sama tapi memperlakukan semua agama itu sama dengan mengedepankan tasamuh (toleransi), kemudian syura (musyawarah) antar agama, dan punya sikap musawah (tidak diskriminatif).
\end{abstract}

Kata Kunci: Moderasi Islam, Pluralisme Agama, Kemajemukan.

\section{PENDAHULUAN}

Moderasi Islam (wasathiyyah) pada saat ini tengah menjadi arus utama dalam ke Islaman di Indonesia. Pasalnya Presiden Jokowi mendukung akan kebijakan mengenai Islam nusantara tersebut. Walaupun Presiden Gusdur atau Abdurrahman Wahid sebelumnya pernah memberikan konsep 
serupa yaitu pribumisasi Islam sekitar 2008 lalu. ${ }^{1}$ Moderasi Islam ini dapat menjawab berbagai problematika dalam keagamaan dan peradaban global. Yang tidak kalah penting bahwa muslim moderat mampu menjawab dengan lantang disertai dengan tindakan damai dengan kelompok berbasis radikal, ekstrimis dan puritan yang melakukan segala halnya dengan tindakan kekerasan. ${ }^{2}$

Tindakan berbasis radikal, ekstrimis dan puritan salah satu penyebabnya keberagaman dalam beragama (Pluralis Beragama). Pluralis beragama ini merupakan pemikiran atau pemahaman tentang keyakinan yang dianut oleh masyarakat di salah satu tempat yang cendrung berbeda-beda. Salah satu negara yang memiliki keberagaman dalam beragama adalah Indonesia yang mempunyai beberapa agama yang diakui. Di samping beragamnya agama, dalam satu agama pun terdapat keragaman yang terealisasi pada berbagai bidang keilmuan dalam agama itu. Misalnya berbeda di dalam fiqih dan dalam pemahaman ketauhidan (ilmu kalam).

Indonesia sebagai negara yang memiliki penduduk muslim terbanyak di dunia menjadi sorotan penting dalam hal moderasi Islam. $^{3}$ Kerukunan umat beragama di Indonesia yang serba pluralis ini ternyata telah dilirik oleh negara-negara seperti negara Arab Saudi, Mesir dan sebagainya, sampai Indonesia mendapat peringkat kedua terbaik dalam kerukunan antar-umat beragama (World Interfaith Harmony Week) 2018 yang diselenggarakan atas amanat Majelis Umum

1 Muhammad Labib Syauqi, 'Islam (Di) Nusantara; Esensi, Genealogi Serta Identitasnya Islam (In) Archipelego; Its Essence, Genealogy, And Identify', ANALISIS: Jurnal Studi Keislaman 15, no. 2 (2015): 321.

2 Khaled Abou El-Fadl, Selamatkan Islam Dari Muslim Puritan (Jakarta: Serambi, 2005). 343

https://support.muslimpro.com/hc/id/articles/11500200608 7-Top-10-Populasi-Umat-Muslim-Terbesar-di-Dunia. Diakses 16 Desember 2018
Perserikatan Bangsa-Bangsa (PBB). ${ }^{4}$ Terlebih lagi Indonesia merupakan contoh model relasi negara dan agama yang berhubungan selaras dan dipahami saling membutuhkan secara timbal balik.

Akan tetapi keberagaman ini menjadi masalah terbesar nantinya jika tidak dihadapi dengan arif dan bijak, bahkan ini akan menimbulkan perseteruan yang berkepanjangan dan dapat menganggu kestabilitasan negara Indonesia itu sendiri sekalipun antar pemeluk agama yang sama.

Maka pada tulisan ini, kajian yang hendak penulis sajikan untuk menjadikan keberagaman agama sebagai aset yang penting bagi negara indonesia adalah bagaimana cara moderat yang ditawarkan oleh Islam dapat menjadi pemersatu dalam pluralisme agama di Indonesia?

\section{PLURALISME AGAMA DI INDONESIA}

Indonesia merupakan negara yang terdiri dari beragam suku, agama dan budaya, atau sering dikenal oleh banyak orang sebagai negara yang majemuk. Kemajemukan ini timbul di tengahtengah masyarakat Indonesia yang bersifat heterogen ini. Hal ini dapat menimbulkan paham pluralism (pluralisme) yang terealisasi dalam masyarakat dan salah satu bentuk dari pluralisme ini adalah Bhineka Tunggal Ika. Akan tetapi pluralisme ini kurang mendapat perhatian masyarakat dan sering dipandang sebelah mata.

Jika ditelaah dari pengertian pluralisme itu, berasal dari bahasa Inggris: pluralism, terdiri dari dua kata plural berarti beragam dan isme berarti paham yang apabila digabungkan memiliki arti beragam pemahaman, atau bermacam-macam paham. Sebutan pluralisme adalah termasuk kata yang ambigu dan memiliki banyak pengertian oleh

4 https://www.merdeka.com/peristiwa/indonesia-raihjuara-dua-program-kerukunan-beragama-pbb.html.Diakses 16 Des 2018 
para ahli. ${ }^{5}$ Franzz Magnis-Suseno menganggap pluralisme sebagai penjelasan keadaan sosial, tetapi menolak kalau pluralisme dijadikan sebagai sikap teologis. ${ }^{6} \mathrm{Hal}$ ini hampir serupa dengan pandangan Moh. Shofan yang menyatakan bahwa pluralisme itu adalah upaya untuk membangun kesadaran sosial dan tidak hanya tentang teologis saja. ${ }^{7}$ Adapun maksud pluralisme itu sendiri secara istilah umum adalah pandangan, pikiran, sikap dan pendirian yang dipunyai seseorang terhadap berbagai realita dan fakta dari perbedaan tersebut. ${ }^{8}$

Pluralisme menghendaki sebuah tatanan yang baik dalam bermasyarakat, sebagaimana disebutkan oleh Abdul Aziz Sachedina dalam buku Pluralisme Perspektif Agama-Agama bahwa istilah pluralisme merupakan salah satu kata yang paling ringkas untuk menyebut suatu tatanan dunia baru di mana perbedaan budaya, sistem kepercayaan, dan nilai-nilai perlu disadari agar warga negara terpanggil untuk hidup berdamai dalam perbedaan dan keragaman. ${ }^{9}$

Pada hakikatnya pluralisme itu tidak selalu hanya berhubungan dengan agama akan tetapi berarti juga sebagai suatu pandangan yang menyatakan keberagaman atau kemajemukan dalam suatu masyarakat baik itu adat, suku dan budaya. Misalnya kemajemukan yang ada di Sumatera Barat, meskipun dalam satu wilayah tapi terdapat keberagaman adat, suku dan agama di masingmasing daerahnya. Suku yang ada di Sumatera Barat memiliki suku induk pada dahulunya yaitu suku Minangkabau, kemudian terpecah menjadi empat

5 Fatonah Dzaki, 'Meluruskan Pemahaman Pluralisme Dan Pluralisme Agama Di Indonesia' 9, no. 1 (2014): 79-94.

${ }^{6}$ Ibid

http://www.academia.edu/17106614/Pluralisme_menuru_pa ra_ahli. Diakses 21 Des 2018

8 Nur Said, 'Nalar Pluralisme John Hick Dalam Keberagaman Global', Fikrah: Fikerah: Jurnal Ilmu Aqidah Dan Studi Keagamaan 3, no. 2 (2015): 22.

${ }_{9}$ Umi Sumbulah, Pluralisme Agama: Makna Dan Lokalitas Pola Kerukunan Antar Umat Beragama, 4th ed. (Malang: UIN Maliki Press, 2013). 33 suku besar di antaranya suku Koto dan Piliang yang dibawa oleh Datuak Katumangguangan, kemudian suku Bodi dan Caniago yang dibawa oleh Datuak Parpatiah Nan Sabatang. Dan setelah empat suku besar itu lahir timbul juga keberagaman suku lainnya yang menimbulkan kemajemukan di tengah masyarakat Sumatra Barat di antaranya suku Guci, Pisang dan sebagainya. ${ }^{10}$ Akan tetapi kemajemukan bukan berarti mencampuradukkan semuanya, tetapi pada kemajemukan terlihat perbedaan yang khas antara yang satu dengan yang lainnya.

Pluralisme sebenarnya tidak memukul rata bahwa semua Agama di Indonesia itu sama. Fatwa MUI tahun 2005 telah membantah tentang pengertian pluralisme yang mengajarkan bahwa semua agama itu sama dan kebenaran terhadap agama itu relatif. ${ }^{11}$ Pendapat MUI ini menimbulkan kontradiksi karena maksud dari pluralisme itu tidaklah seperti yang dimaksud oleh MUI untuk menyamaratakan semua agama itu sama. Oleh karena itu banyak media massa menyajikan tema pluralisme di rubrik opininya dikarenakan tidak suka dengan fatwa MUI tersebut. ${ }^{12}$

Sementara itu Abdurrahman Wahid (Gus Dur), yang dikenal sebagai tokoh pluralisme, menyatakan bahwa pluralisme merupakan pandangan keterbukaan untuk menemukan kebenaran, karena dari keterbukaan akal fikiran akan menimbulkan sifat toleransi. ${ }^{13}$ Dari pernyataan Gus Dur ini dapat dipahami bahwa masyarakat harus bersifat terbuka dengan kondisi Indonesia yang majemuk dari segala sisi termasuk kemajemukan dalam beragama. Keterbukaan dalam

\section{Asal Usul Suku di Minangkabau,} http://sorotindonesia.com/suku-minang-sumatera-barat/.

Diakses 21 Des 2018

11 Firdaus M. Yunus, 'Agama Dan Pluralisme', Jurnal Ilmiah Futura 13, no. 2 (2014): 213-19, https://doi.org/10.22373/jiif.v13i2.72.

12 Umi Sumbulah, Pluralisme Agama: Makna Dan Lokalitas Pola Kerukunan Antar Umat Beragama.

13 Fatonah Dzaki, 'Meluruskan Pemahaman Pluralisme Dan Pluralisme Agama Di Indonesia’. 86 
menerima perbedaan itulah yang melahirkan toleransi dan kedamaian di bumi Indonesia.

Menurut Nucholis Majid pluralisme agama itu adalah sebuah aturan Tuhan yang tidak mungkin dilawan dan tidak mungkin diingkari, ${ }^{14}$ dan pendapat ini selaras dengan pernyataan Djohan Effendi. Menurutnya agama, terutama yang bersumber pada wahyu, diyakini sebagai bersifat ilahiyah. Agama memiliki nilai mutlak. Namun, ketika agama itu dipahami oleh manusia, maka kebenaran agama itu tidak bisa sepenuhnya ditangkap dan dijangkau oleh manusia, karena manusia sendiri bersifat nisbi dan kebenaran agama yang dikatakan oleh manusia itu juga nisbi. ${ }^{15}$ Dari pernyataan Djohan di atas bahwa agama Islam khususnya adalah agama yang benar dengan sumber utamanya al-Qur`an dan Sunnah. Akan tetapi dalam memahami kedua sumber tersebut terdapat kerelatifan.

Akan tetapi secara khusus, pluralisme agama menurut Syamsuddin Arif adalah pandangan, pikiran, keyakinan bahwa agama-agama yang bermacam-macam dan berbeda-beda itu mempunyai kesamaan dari segi ontologi, dan epistemologi. ${ }^{16}$ Untuk mempertegas gagasan ini tokoh pluralisme mencoba menarik kesimpulan dari ayat-ayat Alquran yang berhubungan dengan itu.

Setidaknya ada 2 ayat dalam Alquran yang berkenaan dengan pluralisme ${ }^{17}$ ini yaitu pertama QS Al Baqarah [2]: 62;

"Sesunggubnya orang-orang yang beriman,orangorang Yabudi, orang-orang Nasrani, dan orangorang Shabi'in, ${ }^{18}$ siapa saja diantara mereka

14 Adian Husaini, Wajah Peradaban Barat: Dari Hegemoni Kristen Ke Dominasi Sekular-Liberal (Jakarta: Gema Insani Press, 2005). Hal. 337

15 Fatonah Dzaki, 'Meluruskan Pemahaman Pluralisme Dan Pluralisme Agama Di Indonesia'. 86

16 Said, 'Nalar Pluralisme John Hick Dalam Keberagaman Global'. 317

${ }^{17}$ Idrus Ruslan, 'Etika Islam Dan Semangat Pluralisme Agama Di Era Global', Al-AdY an 5, no. 1 (2010): 7.

18 Shabi'in itu berasal dari kata Shabi' yang artinya yang keluar dari agamanya dan membuat agama baru yang benar-benar beriman kepada Allah, hari kemudian dan beramal shalih, mereka akan menerima pabala dari Tuban mereka, tidak ada kekhawatiran bagi mereka dan tidak pula bersedih hati."

Menurut Said Aqiel Siradj, secara tekstual ayat itu memberikan indikasi atas beragamnya agama. Dalam Al quran agama ini sering disebut dengan al-dien atau al-millah, sekali pun berbeda redaksi kata tetapi maksud dari kata tersebut sama. ${ }^{19}$

Kemudian dalam QS al-Maidah [5]: $69^{20}$ dinyatakan;:

"Sesunggubnya orang-orang mukmin, orang-orang Yahudi, Shabiin dan orang-orang Nasrani, siapa saja (diantara mereka) yang benar-benar saleh, Maka tidak ada kekhawatiran terhadap mereka dan tidak (pula) mereka bersedih hati."

Tokoh pluralisme menafsirkan dua ayat tesebut bahwa pemeluk agama Yahudi, Nasrani, Shabi'in bila beriman kepada Allah swt. dan beriman kepada hari kemudian dan beramal shalih,semua akan selamat. Bahkan pemeluk agama apapun mendapat keselamatan dalam kehidupannya. $^{21}$

Akan tetapi menurut penafsiran Buya Hamka, ayat ini menjelaskan janjian yang adil dari Tuhan kepada seluruh manusia, tidak pandang dalam agama yang mana mereka hidup, namun mereka masing-masing akan mendapat ganjaran atau pahala di sisi Tuhan, sepadan dengan iman dan amal shalih yang telah mereka kerjakan itu. ${ }^{22}$ Akan tetapi, Hamka melanjutkan pendapatnya dengan mengatakan ayat tersebut (Surat Almaidah ayat 69) telah dimansukh oleh Q.S Ali Imran ayat 85 dengan

dianggapnya lebih sempurna. "...dan orang-orang Nashara," adalah kaumnya Nabi Isa as. (Jurnal pluralisme dalam problema)

${ }^{19}$ Ruslan, 'Etika Islam Dan Semangat Pluralisme Agama Di Era Global'.

20 Achmad, 'Pluralisme Dalam Problema', Jurnal Sosial Humaniora 7, no. 2 (2014): 189-204.

21 Ibid

22

http://muhammadiyahstudies.blogspot.com/2012/04/hamka -tentang-ayat-62-al-baqarah-dan.html. Diakses 22 Des 2018 
alasan untuk memperkuat penafsiran ayat tersebut, bahwa agama Islam adalah agama yang paling benar. Bunyi dari Q.S Ali Imran ayat 85;:

"Barangsiapa mencari agama selain agama Islam, Maka sekali-kali tidaklah akan diterima (agama itu) daripadanya, dan Dia di akhirat Termasuk. orang-orang yang rugi.

Adapun faktor-faktor yang menyebabkan pluralisnya agama ini sesuai dengan yang dikutip dari Fatonah Dzakie, ${ }^{23}$ di antaranya; yang pertama, faktor internal yaitu keyakinan seseorang yang mutlak dan absolut terhadap apa yang diyakini dan diimaninya merupakan hal yang wajar. Sikap absolutisme agama tak ada yang mempertantangkannya hingga muncul teori tentang relativisme agama. Pemikiran relativisme ini merupakan sebuah sikap pluralisme terhadap agama.

Kemudian yang kedua, dari faktor eksternal munculnya pemikiran mengenai masalah liberalisme yang menyuarakan kebebasan, toleransi, kesamaan, dan pluralisme. Liberalisme inilah yang menjadi cikal bakal pluralisme ini. Karena pada hakikatnya konsep pluralisme ini berasal dari dunia barat yang berpaham liberal dan sekularistik. Bagi mereka orang-orang barat kebenaran akan suatu agama itu bersifat relatif. ${ }^{24}$

Faktor ketiga adalah maraknya studi-studi ilmiah modern terhadap agama-agama dunia, atau yang sering dikenal dengan perbandingan agama. Diantara temuan dan kesimpulan penting yang telah dicapai adalah bahwa agama di dunia hanyalah merupakan ekspresi atau manifestasi yang beragam. Maksud dari temuan itu bahwa setiap agama itu tidak terlepas dari kemajemukan masyarakat yang hidup di dunia. Terlebih lagi di era keterbukaan dan

${ }^{23}$ Fatonah Dzaki, 'Meluruskan Pemahaman Pluralisme Dan Pluralisme Agama Di Indonesia'. 82-83

24 Baco Sarluf, 'Pluralisme Adalah Fundamentalisme', Dialektika 11, no. 2 (2018): 66-74. demokrasi, semakin warna-warni keyakinan dan pemikiran seseorang dan kelompok. ${ }^{25}$

Di Indonesia pluralisme agama menuai kontroversi yang hangat diperbincangkan. Ada kelompok yang menyatakan pro dengan pluralisme agama dan ada juga yang kontra dengan pluralisme agama. Pasalnya bagi orang yang kontra dengan pluralisme agama mereka beranggapan bahwa pluralisme agama ini cendrung liberalis dan sekularistik, dikarenakan pluralisme ini lahir dari dua paham tersebut. Kemudian kelompok yang kontra juga beranggapan bahwa pluralisme dapat mengakibatkan bercampur baurnya satu agama dengan agama yang lain. ${ }^{26}$ Dan bagi kelompok yang pro dengan pluralisme agama ini beranggapan bahwa pluralisme agama ditujukan untuk kerukunan antar umat dalam bernegara.

\section{MODERASI ISLAM}

Islam merupakan agama yang paling diridhoi oleh Allah swt. dan agama yang rahmathan lil alamin (rahmat buat semesta alam) yang dibawa oleh Nabi Muhammad Saw. ${ }^{27}$ Sesuai dengan Q.S Al Anbiya ayat 107;

'Dan Tiadalah Kami mengutus kamu (mubammad), melainkan untuk (menjadi) rahmat bagi semesta alam".

Tafsir Ibnul-Qoyyim al-Jauziyah menerangkan bahwa semesta raya mendapat manfaatnya dengan diutusnya Muhammad Saw, dan orang-orang yang mengikuti beliau dapat meraih kemuliaan dunia akhirat. Oleh karena itu, orangorang munafik dan non muslim pun mendapat manfaat berupa terjaga darahnya, hartanya, keluarga dan kehormatannya, serta memperoleh perlakuan

25 https:/www.uinjkt.ac.id/id/ragam-ekspresiberagama/. Diakses 29 Des 2018

26

https://student.cnnindonesia.com/inspirasi/20180115100508

-454-268836/pluralisme-adalah-aset-bangsa-indonesia.

Diakses 29 des 2018

27 Abd. Malik Usman, 'Islam Rahmah Dan Wasathiyah (Paradigma Keberislaman Inklusif, Toleran Dan Damai)', Humanika 15, no. 1 (2015): 1-12. 
sama dengan kaum muslimin. Jadi, Islam adalah rahmat buat semua, namun buat orang beriman, akan mendapat manfaat dunia dan akhirat. ${ }^{28}$

Sedangkan dalam Fathul Qadir, Muhammad bin Ali as-Syaukany menafsirkan bahwa satu-satunya alasan Allah mengutus Nabi Muhammad Saw adalah sebagai rahmat yang luas, karena Allah mengutusnya dengan membawa sesuatu yang menjadi sebab kebahagiaan duniaakhirat. $^{29}$

Agama Islam sebagai rahmatan lil alamin ini pastinya membawa perubahan yang sangat besar ke atas bumi ini, contohnya saja pada saat Islam mulai berkembang di bumi nusantara ini. Pada dahulunya Indonesia merupakan negara yang mayoritas beragama Hindu dan Budha karena pada masa itu kerajaan-kerajaan hindu menguasai satu persatu wilayah di Indonesia. Salah satu diantarannya kerajaan Majapahit yang hampir menguasai daratan nusantara pada masa itu. Kerajaan yang dpimpin oleh Hayam Wuruk ini, dengan Mahapatih Gajah Mada yang menjadi simbol dari peradaban lahirnya nusantara ini.

Pasca runtuhnya kerjaan Majapahit ini kemudian lahirlah kerajaan Islam seperti kerajaan Demak yang dianggap sebagai salah satu kerajaan Islam terbesar di Indonesia pada saat itu. ${ }^{30}$ Sebelum kerajaan Islam mulai membumi di Indonesia, Islam tidak terlepas dari tiga teori atau pendapat mengenai masuknya Islam ke Indonesia

Pertama, teori Gujarat, yang menyatakan bahwa Islam ke Indonesia pada abad ke $13 \mathrm{M}$ yang dikemukakan oleh J.Pijnapel, ${ }^{31}$ ia berpendapat bahwa yang membawa Islam itu ialah pedagang dari Gujarat yang memeluk Islam dan berdagang ke

28 muslim.or.id/Alquran lisan-rabmatan lil-alamin.html. Diakses 22 des 2018

29 Usman, 'Islam Rahmah Dan Wasathiyah (Paradigma Keberislaman Inklusif, Toleran Dan Damai)'.

30 https://umrohhajiwisata.com/kerajaan-Islam-diindonesia/amp/ Diakses 22 Des 2018

31 Tokoh sarjana dari Belanda dari Universitas Leiden abad ke-19 M dunia timur, termasuk Indonesia. ${ }^{32}$ Kemudian teori ini juga dikembangkan oleh J.P. Moquetta dengan menemukan bukti batu nisan Sultan Malik Alshaleh di Pasai, Aceh.

Kedua, teori Persia, bahwa Islam dibawa oleh pedagang dari Persia bukan dari Gujarat. Dibuktikan dengan tradisi di Indonesia yang dianggap memiliki kesamaan. Contohnya saja peringatan 10 Muharram yang bernama Tabuik (tabut) di beberapa wilayah Sumatra (Seperti Sumatera Barat dan Jambi). ${ }^{33}$

Ketiga, teori Makkah atau teori arab, menyatakan bahwa Islam masuk ke Indonesia pada abad ke $7 \mathrm{M}$, dibawa oleh orang-orang arab yang memiliki semangat dalam menyebarkan agama Islam. Dengan salah satu bukti otentik dari kerajaan Samudra Pasai, yang pada kala itu bermazhab Syafi i yang merupakan mazhab populer di Arab dan Mesir. Pendapat ini didukung oleh tokoh Van Leur, Anthony H. Johns dan Buya hamka. ${ }^{34}$

Terakhir yaitu teori Cina yang dicetuskan oleh Slamet Mulyana dan Sumanto Al Qurtuby, dengan salah satu bukti di antaranya catatan Cina yang menyatakan bahwa pelabuhan-pelabuhan di Nusantara pertama kali diduduki oleh Pedagang China. ${ }^{35}$

Memang menurut kajian sejarah bahwa Islam masuk ke Nusantara pertama kali tercatat sudah sejak abad ketujuh, pendapat ini banyak didukung oleh di antaranya Harry W. Hazard, Naquib al-Attas, S.Q. Fatimy, W.P. Groeneveld dan yang lainnya, akan tetapi Islam di Nusantara perkembangannya menjadi massif adalah ketika sebagian besar penduduk Champa yang beragama

32

http://m.kumparan.com/muhamad-aliefraflie/sejarah-masuknya-Islam-di-indonesia.amp. Diakses 22 des 2018

334 Teori Masuknya Islam ke Nusantara, Blog.ruangguru.com. Diakses 22 Des 2018

34 Teori Masuknya Islam ke Indonesia, wordpress.com Diakses 22 Des 2018

35 Ibid 
Islam berbondong-bondong menuju ke wilayah Nusantara berbarengan dengan momentum Wali Songo yang mensyi'arkan Islam secara serentak dan terang-terangan yaitu sekitar abad 15 Masehi. ${ }^{36}$

Dari fakta-fakta yang tertuang di atas dapat dijadikan bukti bahwa peradaban Islam di Indonesia itu mulai dibawa oleh orang-orang dari Gujarat, Arab, Persia dan Cina, dan pada hakikatnya Islam yang dibawa oleh orang-orang tersebut tidaklah mengarah pada titik Islam yang beraliran keras atau radikal seperti yang kita ketahui saat ini yaitu Islam radikal. Terlebih lagi Wali Songo sebagai icon penyebar Islam di pulau Jawa mengedepankan prinsip wasathiyah atau sering diterjemahkan dengan kata moderat. ${ }^{37}$ Jadi di sini menurut Wan Kamal Mujani, timbul istilah penyebaran Islam yang mengedepankan prinsip moderat ini dengan nama Islam Moderat. ${ }^{38}$ Sesuai dengan firman Allah QS Al Baqarah [2]:143;

"Dan demikian (pula) Kami telah menjadikan kamu (umat Islam), umat yang adil dan pilihan ${ }^{39}$ agar kamu menjadi saksi atas (perbuatan) manusia dan agar Rasul (Muhammad) menjadi saksi atas (perbuatan) kamu. dan Kami tidak menetapkan kiblat yang menjadi kiblatmu (sekarang) melainkan agar Kami mengetabui (supaya nyata) siapa yang mengikuti Rasul dan siapa yang membelot. dan sungguh (pemindahan kiblat) itu terasa Amat berat, kecuali bagi orangorang yang telah diberi petunjuk oleh Allah; dan Allah tidak akan menyia-nyiakan imanmu. Sesungguhnya Allah Maha Pengasib lagi Maha Penyayang kepada manusia".

36 Muhammad Labib Syauqi, 'Islam (Di) Nusantara; Esensi, Genealogi Serta Identitasnya Islam (In) Archipelego; Its Essence, Genealogy, And Identify', ANALISIS: Jurnal Studi Keislaman 15, no. 2 (2015): 328.

${ }^{37}$ Syauqi. 328

38 Wan Kamal Mujani, Ermy Azziaty Rozali, and Nor Jamaniah Zakaria, 'The Wasatiyyah (Moderation) Concept: Its Implementation In Malaysia', Mediterranean Journal of Social Sciences 6, no. 4 (2015): $66-72$, https://doi.org/10.5901/mjss.2015.v6n4s2p66.

39 Umat Islam dijadikan umat yang adil dan pilihan, karena mereka akan menjadi saksi atas perbuatan orang yang menyimpang dari kebenaran baik di dunia maupun di akhirat.
Islam Moderat atau yang dimaksud juga Islam Wassatiyah, berasal dari dua kata Islam dan wassatiyah. Islam sebagaimana yang diketahui adalah agama yang penuh dengan keberkahan,dan agama yang dibawa oleh Nabi Muhammad Saw. Islam merupakan agama mayoritas yang ada di Indonesia dengan penduduk terbanyak di dunia saat ini menurut situs Muslim Pro. ${ }^{40}$

Sedangkan Wassatiyah berasal dari kata wasa-ta yang mengandung arti kebajikan, keadilan dan kebaikan. Menurut Muhammad Qutb berarti keseimbangan, maksudnya keseimbangan diantara keimanan dan realita yang dapat dirasai dengan panca indra. ${ }^{41}$

Menurut istilah wassatiyah menurut Yusuf al-Qaradhawi ialah Pertengahan antara dua pihak yang saling berlawanan dan saling menyingkirkan satu sama lain dan setiap pihak tidak mengambil lebih dari hak-hak yang sepatutnya. Dan ditambahkan lagi oleh Yusuf Qaradhawi bahwa manhaj wassatiyah, kesederhanaan dalam sesuatu, baik itu akidah, muamalat, dan sebagainya. ${ }^{42}$

Ibnu 'Asyur mendefinisikan kata "wasath" dengan dua makna. Pertama, definisi menurut etimologi, kata wasath berarti sesuatu yang ada di tengah, atau sesuatu yang memiliki dua belah ujung yang ukurannya sebanding. Kedua, definisi menurut terminologi bahasa,makna wasath adalah nilai-nilai Islam yang dibangun atas dasar pola pikir yang

40

https;//support.muslimpro.com/hc/id/articles/11500200608 7-Top-10-Populasi-Umat-Muslim-Terbesar-didunia?mobile_site=true. Diakses 15 Des 2018

${ }^{41}$ Mohd Annuar Ramli, Muhamad Sayuti Mansor, and Lutfi Juwaini, 'Pendekatan Wasatiyyah Bagi Menangani Ikhtilaf Fiqh Dalam Kalangan Masyarakat Islam Nusantara' (Seminar Antarabangsa "Islam di Alam Melayu kali ke-V." College of Islamic Studies Prince of Songkla University, Pattani Thailand: UM Research Repository, 2015), http://eprints.um.edu.my/14748/.

42 Ramli, Muhamad Sayuti Mansor, and Lutfi Juwaini. 
lurus dan pertengahan, tidak berlebihan dalam hal tertentu. ${ }^{43}$

Mengenai Islam moderat bila Mengacu pada makna etimologisnya, kategorisasi Islam moderat sebetulnya bisa saja dilakukan secara simplifikatif. Dari sejumlah gerakan Islam di Indonesia sejak pra kemerdekaan hingga kini, terdapat kelompok yang dapat digolongkan sebagai lunak dan tidak ekstrem (moderat). Dalam sejarah kolonialisme di Indonesia, Muhammadiyah dapat disebut moderat, karena lebih menggunakan pendekatan pendidikan dan transformasi budaya. ${ }^{44}$ Begitu pun juga dengan Nahdathul Ulama yang merupakan moderat yang tidak jauh berbeda dengan Muhammadiyah. Pada Nahdathul Ulama sering mengedepankan prinsip Ahlul Sunnah WalJamaah yang mencakup disegala bidang.

Ciri-ciri dari Islam Wassatiyah ini menurut Yusuf Qaradhawi, sebagaimana dikutip oleh Muhd. Nashiruddin antara lain; ${ }^{45}$

1. Meyakini adanya hikmah di balik syari'at serta kandungannya untuk kemaslahatan makhluk.

2. Selalu menginterkoneksikan antara satu nash/hukum dengan nash/hukum yang lainnya atau mendukung pemahaman Islam yang komprehensif, ${ }^{46}$ karena apabila tidak komprehensif maka moderat yang dimaksudkan akan menyeleweng menjadi radikalisme dan akan berubah posisi dari pertengahan menjadi berat sebelah.

3. Bersikap moderat (pertengahan) pada setiap perkara agama dan dunia.

43 Afrizal Nur and Mukhlis Lubis, 'Konsep Wasathiyah Dalam Al-Quran; (Studi Komparatif Antara Tafsir Al-Tahrir Wa At-Tanwir Dan Aisar At-Tafasir)', An-Nur 4, no. 2 (2015): 208.

44 Rahmatullah, 'Islam Moderat Dalam Perdebatan', Dialog 71, no. 1 (2011): 42-43.

${ }_{45}$ Muhd. Nashiruddin, FIKIH MODERAT DAN VISI KEILMUAN SYARI'AH DI ERA GLOBAL (Konsep Dan Implementasinya Pada Fakultas Syariah IAIN Surakarta) (Surakarta: IAIN Surakarta, n.d.). 36

46 Rahmatullah, 'Islam Moderat Dalam Perdebatan'. 46
4. Selalu mengkorelasikan nash-nash agama dengan realita-realita yang kongkrit dan kontemporer.

5. Selalu mengedepankan yang termudah dan mengambil yang termudah.

6. Keterbukaan (inklusifisme) dan toleran (tasammuh) dengan kelompok yang berbeda pendapat.

Adapun ciri-ciri lain tentang wassatiyah yang disampaikan oleh Afrizal Nur dan Mukhlis: ${ }^{47}$

1. Tawassuth (mengambil jalan tengah), yaitu pemahaman dan pengamalan yang tidak ifrath (berlebih-lebihan dalam beragama) dan tafrith (mengurangi ajaran agama).

2. Tawazun (berkeseimbangan), yaitu pemahaman dan pengamalan agama secara seimbang yang meliputi semua aspek kehidupan, baik duniawi maupun ukhrawi, tegas dalam menyatakan prinsip yang dapat membedakan antara inhira, (penyimpangan,) dan ikhtilaf (perbedaan).

3. I'tidâl (lurus dan tegas), yaitu menempatkan sesuatu pada tempatnya dan melaksanakan hak dan memenuhi kewajiban secara proporsional.

4. Tasamub (toleransi), yaitu mengakui dan menghormati perbedaan, baik dalam aspek keagamaan dan berbagai aspek kehidupan lainnya.

5. Musawah (egaliter), yaitu tidak bersikap diskriminatif pada yang lain disebabkan perbedaan keyakinan, tradisi dan asal usul seseorang.

6. Syura (musyawarah), yaitu setiap persoalan diselesaikan dengan jalan musyawarah untuk mencapai mufakat dengan prinsip menempatkan kemaslahatan di atas segalanya.

7. Ishlah (reformasi), yaitu mengutamakan prinsip reformatif untuk mencapai keadaan lebih baik yang mengakomodasi perubahan dan kemajuan zaman dengan berpijak pada kemaslahatan

47 Nur and Mukhlis Lubis, 'Konsep Wasathiyah Dalam Al-Quran; (Studi Komparatif Antara Tafsir Al-Tahrir Wa AtTanwir Dan Aisar At-Tafasir)'. 212 
umum (mashlahah 'ammah) dengan tetap berpegang pada prinsip al-mubafarhah ala alqadimi al-shalih wa al-akbdzu bi al-jadidi al-ashlah (melestarikan tradisi lama yang masih relevan, dan menerapkan hal-hal baru yang lebih relevan).

8. Aulawiyah (mendahulukan yang prioritas), yaitu kemampuan mengidentifikasi hal ihwal yang lebih penting harus diutamakan untuk diterapkan dibandingkan dengan yang kepentingannya lebih rendah.

9. Tathawnur wa Ibtikar (dinamis dan inovatif), yaitu selalu terbuka untuk melakukan perubahanperubahan kearah yang lebih baik.

Jika kita bandingkan antara ciri-ciri yang dikemukakan oleh Yusuf Qaradhawi dengan Afrizal Nur, ciri-ciri yang lebih memperlihatkan wajah dari Islam wasattiyah itu adalah pendapat dari Afrizal Nur, karena ciri-ciri yang disebutkan oleh Afrizal, banyak mempunyai relevansi dengan arti Islam wassatiyah itu sendiri yang cendrung toleransi, egaliter, musyawarah dan lain sebagainya.

\section{MODERASI ISLAM DALAM PLURALISME AGAMA DI INDONESIA}

Pluralisme tidak dapat dikaitkan dengan adat, budaya, dan suku yang ada dimasing-masing daerahdi Indonesia. Tidak mungkin adat yang ada disuatu daerah semisal yang berada di Sumatera Barat sama dengan adat yang berada didaerah Jawa tengah. Akan tetapi istilah pluralisme hanya cocok jika dikaitkan dengan agama, karena sesuai dengan konsep diatas bahwa agama itu memiliki beberapa kesamaan baik itu dari ontologi maupun epistimologi sesuai dengan pendapat yang diajukan oleh Syamsuddin Arif. ${ }^{48}$

Adapun beberapa kesamaan yang dimiliki oleh agama-agama yang berada di Indonesia antara lain yang pertama, bahwa semua agama memiliki

48 Said, 'Nalar Pluralisme John Hick Dalam Keberagaman Global'. 379 tuhan. Setiap agama percaya bahwa ada sesuatu zat yang menciptakan dunia ini, dan ada sesuatu yang harus disembah.

Kemudian persamaan kedua yaitu samasama memiliki kitab suci dan tempat ibadah. Tujuan dari adanya kitab suci bagi setiap umat beragama yaitu sebagai pedoman dalam mengatur jalannya kehidupan manusia yang terkadang menyimpang dari yang sudah dimaktubkan dalam kitab mereka masing-masing. Selain itu agama juga memiliki tempat ibadah, yang tentunya membantu mereka dalam menjalankan ibadah-ibadahnya, seperti agama Islam dalam menjalankan Ibadah Sholat Berjamaah, mereka membutuhkan mesjid atau musholla dalam menjalankan ibadah tersebut.

Pandangan yang dikemukan oleh Nurcholis Madjid dan Djohan mengenai pluralisme agama ini sepertinya selaras dengan Islam, karena Islam menganggap bahwa agama itu adalah sunatullah dan bersifat mutlak ${ }^{49}$. Islam merupakan agama yang membawa keberkahan serta agama yang menjunjung tinggi kedamaian diatas muka bumi ini. Sebagai agama yang mayoritas di Indonesia pastinya Islam membawa berkah terhadap agama yang minoritas. Buktinya dapat terlihat dalam kehidupan bebangsa dan bernegara. Islam selalu toleransi terhadap kaum minoritas yang melakukan ibadahnya masing-masing, seperti perayaan Natal, perayaan hari raya waisak dan lain sebagainya. Dibalik toleransi yang disuguhkan oleh agama Islam dalam kehidupan ini, Islam juga tidak pernah memaksa orang-orang untuk memeluk agama Islam itu sendiri, karena sesuai dengan firman allah Q.S Al Baqarah ayat 256

"Tidak ada paksaan untuk (memasuki) agama (Islam); Sesunggubnya telah jelas jalan yang benar daripada jalan yang sesat".

49

https://www.uin.malang.ac.id/blog/post/read/131101/relati vitas-dalam-ajaran-agama-agenda-kerukunan-antarumat-daninterumat-beragama.html. Diakses 29 des 2018 
Diriwayatkan dari Ibnu Abbas, ia berkata tentang sebab diturunkannya ayat ini, "Ayat ini diturunkan berkaitan dengan salah seoarang Anshar (sahabat Nabi dari Madinah) dari Bani Salim bin Auf. Al-Hushaini mengatakan, 'Sahabat ini memiliki dua orang anak laki-laki yang beragama Nasrani dan dia seorang muslim. Lalu ia berkata kepada Nabi shallallahu 'alaihi wa sallam, bolehkah aku memaksa keduanya karena mereka menolak agama kecuali agama Nasrani. Allah pun menurunkan ayat ini." (Tafsir Ibnu Katsir). ${ }^{50}$

Dari pernyataan Islam itu selaras dengan pernyataan umum tentang hak asasi manusia oleh Majlis Umum PBB (Universal Declaration of Human Rights), yang salah satu isinya mengenai kebebasan dalam beragama. ${ }^{51}$ Dari fakta diatas terlihat bahwa Islam merupakan agama yang tidak memaksa dan tidak menuntut orang untuk masuk dalam ajarannya.

Selain dari pada agama Islam di Indonesia juga terdapat berbagai agama lainnya yaitu agama Kristen, Hindu, Budha, Konghucu dan lain sebagainya, karena itu Indonesia disebut juga dengan pengakuan terhadap banyak agama. Islam menawarkan beberapa konsep yang akan meningkatkan kualitas seseorang dalam kehidupan beragama.

Konsep yang pertama yaitu konsep tasamuh (toleransi), sesuai dengan ciri-ciri moderasi Islam di atas dapat dipastikan jika antar umat beragama di Indonesia sudah hidup berdampingan dan saling toleransi, akan menjaga kestabilitasan antar umat beragama dan menjaga kerukunan antar umat beragama.

Konsep kedua yang ditawarkan oleh Islam terhadap kehidupan pluralisme agama ini yaitu

50 https://aslibumiayu.net/11944-tidak-ada-paksaanuntuk-memeluk-Islam-lalu-kenapa-terjadi-peperangan.html. Diakses 29 des 2018

https://id.wikipedia.org/wiki/Pernyataan_Umum_tentang_H ak-Hak_Asasi_Manusia. Diakses 29 Des 2018 konsep Syura (musyawarah), ketika terjadi sesuatu persengketaan atau perselisihan antar umat beragama, akan lebih baik diselesaikan dengan cara musyawarah tanpa adanya perkelahian. Konsep syura ini juga digunakan dalam kehidupan pluralis ini akan dapat menyelesaikan semua masalah yang ada nantinya.

Kemudian konsep terakhir yang diberikan oleh Islam yaitu musawah (egaliter), yaitu tidak bersikap diskriminatif pada yang lain disebabkan perbedaan keyakinan, tradisi dan asal usul seseorang. Dengan konsep-konsep yang ada ini pastinya dapat mempererat hubungan silaturahmi antar umat beragama, sekalipun berbeda dalam keyakinan.

\section{PENUTUP}

Islam tidak menganggap semua agama itu sama tapi memperlakukan semua agama itu sama, dan ini sesuai dengan konsep-konsep dari Islam wasattiyah itu sendiri yaitu konsep egaliter atau tidak mendiskriminasi agama yang lain. Dan adapun cara-cara moderat yang dimaksudkan itu adalah Konsep yang pertama yaitu konsep tasamuh (toleransi), sesuai dengan ciri-ciri moderasi Islam di atas dapat dipastikan jika antar umat beragama di Indonesia sudah hidup berdampingan dan saling toleransi, akan menjaga kestabilitasan antar umat beragama dan menjaga kerukunan antar umat beragama.

Konsep kedua yang ditawarkan oleh Islam terhadap kehidupan pluralisme agama ini yaitu konsep Syura (musyawarah), ketika terjadi sesuatu persengketaan atau perselisihan antar umat beragama, akan lebih baik diselesaikan dengan cara musyawarah tanpa adanya perkelahian. Konsep syura ini juga digunakan dalam kehidupan pluralis ini akan dapat menyelesaikan semua masalah yang ada nantinya.

Kemudian konsep terakhir yang diberikan oleh Islam yaitu musawah (egaliter), yaitu tidak bersikap diskriminatif pada yang lain disebabkan 
perbedaan keyakinan, tradisi dan asal usul seseorang. Dengan konsep-konsep yang ada ini pastinya dapat mempererat hubungan silaturahmi antar umat beragama, sekalipun berbeda dalam keyakinan.

\section{DAFTAR KEPUSTAKAAN}

Achmad. 'Pluralisme Dalam Problema'. Jurnal Sosial Humaniora 7, no. 2 (2014): 189-204.

El-Fadl, Khaled Abou. Selamatkan Islam Dari Muslim Puritan. Jakarta: Serambi, 2005.

Fatonah Dzaki. 'Meluruskan Pemahaman Pluralisme Dan Pluralisme Agama Di Indonesia' 9, no. 1 (2014): 79-94.

Husaini, Adian. Wajah Peradaban Barat: Dari Hegemoni Kristen Ke Dominasi Sekular-Liberal. Jakarta: Gema Insani Press, 2005.

Mujani, Wan Kamal, Ermy Azziaty Rozali, and Nor Jamaniah Zakaria. 'The Wasatiyyah (Moderation) Concept: Its Implementation In Malaysia'. Mediterranean Journal of Social Sciences 6, no. 4 (2015): 66-72. https://doi.org/10.5901/mjss.2015.v6n4s2 p66.

Nashiruddin, Muhd. FIKIH MODERAT DAN VISI KEILMUAN SYARI'AH DI ERA GLOBAL (Konsep Dan Implementasinya Pada Fakultas Syari'ab IAIN Surakarta). Surakarta: IAIN Surakarta, n.d.

Nur, Afrizal, and Mukhlis Lubis. 'Konsep Wasathiyah Dalam Alquran; (Studi Komparatif Antara Tafsir Al-Tahrir Wa AtTanwir Dan Aisar At-Tafasir)'. An-Nur 4, no. 2 (2015): 21.

Rahmatullah. 'Islam Moderat Dalam Perdebatan'. Dialog 71, no. 1 (2011): 40-48.

Ramli, Mohd Annuar, Muhamad Sayuti Mansor, and Lutfi Juwaini. 'Pendekatan Wasatiyyah Bagi Menangani Ikhtilaf Fiqh Dalam Kalangan Masyarakat Islam Nusantara'. Pattani Thailand: UM Research Repository, 2015. http:/ / eprints.um.edu.my/14748/.
Ruslan, Idrus. 'Etika Islam Dan Semangat Pluralisme Agama Di Era Global'. AlAdYan 5, no. 1 (2010): 7.

Said, Nur. 'Nalar Pluralisme John Hick Dalam Keberagaman Global'. Fikrab: Fikerah: Jurnal Ilmu Aqidah Dan Studi Keagamaan 3, no. 2 (2015): 22.

Sarluf, Baco. 'Pluralisme Adalah Fundamentalisme'. Dialektika 11, no. 2 (2018): 66-74.

Syauqi, Muhammad Labib. 'Islam (Di) Nusantara; Esensi, Genealogi Serta Identitasnya Islam (In) Archipelego; Its Essence, Genealogy, And Identify'. ANALISIS: Jurnal Studi Keislaman 15, no. 2 (2015): 321-30.

Sumbulah, Umi. Pluralisme Agama: Makna Dan Lokalitas Pola Kerukunan Antar Umat Beragama. 4th ed. Malang: UIN Maliki Press, 2013.

Usman, Abd. Malik. 'Islam Rahmah Dan Wasathiyah (Paradigma Keberislaman Inklusif, Toleran Dan Damai)'. Humanika 15, no. 1 (2015): 1-12.

Yunus, Firdaus M. 'Agama Dan Pluralisme'. Jurnal Ilmiah Futura 13, no. 2 (2014): 213-19. https://doi.org/10.22373/jiif.v13i2.72.

http://www.academia.edu/17106614/Pluralisme_ menuru_para_ahli . Diakses 21 Des 2018

http://sorotindonesia.com/suku-minang-sumaterabarat/. Diakses 21 Des 2018

http://muhammadiyahstudies.blogspot.com/2012/ 04/hamka-tentang-ayat-62-al-baqarahdan.html. Diakses 22 Des 2018 https:/www.uinjkt.ac.id/id/ragam-ekspresiberagama/. Diakses 29 Des 2018

https://student.cnnindonesia.com/inspirasi/20180 115100508-454-268836/pluralisme-adalahaset-bangsa-indonesia. Diakses 29 des 2018 muslim.or.id/Alquran lisan-rahmatan lilalamin.html. Diakses 22 des 2018

http://regional.kompas.com/read/2011/04/21/17 544955/Majapahit.Awal.Peradaban.Nusanta ra. Diakses 22 Des 2018 
https://umrohhajiwisata.com/kerajaan-Islam-diindonesia/amp/ Diakses 22 Des 2018

http://m.kumparan.com/muhamad-aliefraflie/sejarah-masuknya-Islam-diindonesia.amp. Diakses 22 des 2018 4 Teori Masuknya Islam ke Nusantara, Blog.ruangguru.com. Diakses 22 Des 2018

wordpress.com. Teori Masuknya Islam ke Indonesia, Diakses 22 Des 2018

https; / support.muslimpro.com/hc/id/articles/11 5002006087-Top-10-Populasi-Umat-

Muslim-Terbesar-di-

dunia?mobile_site=true. Diakses 15 Des 2018

https://www.uin.malang.ac.id/blog/post/read/131 101 / relativitas-dalam-ajaran-agama-agendakerukunan-antarumat-dan-interumatberagama.html. Diakses 29 des 2018 https://aslibumiayu.net/11944-tidak-ada-paksaanuntuk-memeluk-Islam-lalu-kenapa-terjadipeperangan.html. Diakses 29 des 2018 https://id.wikipedia.org/wiki/Pernyataan_ Umum_tentang_Hak-Hak_Asasi_Manusia. Diakses 29 Des 2018 